school will also be used for advanced craft training and also for third-year apprentices to ensure that experience gained in the previous two years in the workshops is firmly established in the minds of the apprentices, that misconceptions can be rectified and new developments taught. 'The school, which provides for forty-five to fifty students, comprises a machineshop, fitting sections and a lecture room, and the shops are laid out to enable a wide range of work in plant, industrial, medical and aircraft fields to be covered. It can also be used for intensive courses for the up-grading of fitters, machinists and inspectors, and also for the teaching of new techniques to staff in general. The Company works in close association with the West Ham College of Technology, South West Essex Technical College, Enfield Technical College, Harlow Technical College and the University of London in the provision of sandwich courses.

\section{Electrical Energy}

THE first issue of a new monthly electrical journal, Electrical Energy, appeared in September. This publication is, in some respects, a companion journal to Electronic Engineering, as it is published by the same organization and has common editorship (London: Morgan Brothers (Publishers), Ltd. 3s.). It is stated in the foreword to the first issue that it is designed for the professional engineer engaged in research, development, design and manufacture. The articles in the first number cover a fairly wide range of subjects; one deals with the solution of electric field problems using a digital computer, another with modern methods of excitation control for large synchronous machines, and a third describes the principles of operation of the magnetic amplifier. The standard of these articles is pitched at a level which should satisfy a reader possessing a good scientific background. There are, in addition, short articles and notes dealing with items of current interest concerning industrial developments and new electrical equipment, and, finally, a group of book reviews. The journal is well produced and attractive. It is, perhaps, rather remarkable that there should have existed, to-day, a gap in the coverage of the general field of electrical engineering which a new journal could be designed to fill. There was, however, a need for a periodical which would deal with electrical power in all its aspects and would provide especially for more detailed theoretical treatments of technological topics than are, nowadays, appropriate to the old-established weekly journals which serve the electrical industry so well. The declared policy of Electrical Energy and the quality of its early issues suggest that it will meet this need, and on that ground alone it should be heartily welcome.

\section{Physics in Medicine and Biology}

The first issue of Physics in Medicine and Biology, a new quarterly journal in the same format as the Philosophical Magazine, is dated for July (edited by Prof. J. E. Roberts. London: Taylor and Francis, Ltd. f3 10s. a year). The journal, which is the official publication of the Hospital Physicists Association, is intended for papers on topics in the borderline fields between physics and the biological and medical sciences, which cannot easily be classified for existing periodicals. It will publish original papers and review articles on studies of the physical properties of living matter, and on the applications of physics and physical techniques to problems in medicine, biology and physiology. In addition, it will publish instru- ment notes, book reviews, letters to the Editor, and notes on work in progress. An important feature, which will take 20-25 per cent of the space in each issue, is the Abstracts Section under the editorship of W. A. Langmead. 'These abstracts are taken from a very wide range of journals; in the first issue 130 journals were abstracted. The subtitles of the Abstracts Section give a good indication of the scope of the whole journal: radiobiology, radiotherapy, radiodiagnosis, radioisotopes (biological and clinical aspects), radioisotopes (physical and clinical aspects), radiation dosimetry, physiology, general physics and instrumentation. The first issue contains a review of recent advances in electrophoretic separation methods, and papers on dos meter calibrations, microspectro. photometry, a profile counter, and $\alpha$-track autoradiography. The instrumental note is concerned with the specifications of nucleonic instruments which have clinical applications. Although with such a very wide field only a limited number of papers will be of interest to any one worker, it seems probable that, if the high standard of the first issue is maintained, the journal will be well received by many of the growing number of workers interested in that field.

\section{Priestley in the United States}

THE home of Joseph Priestley has been acquired and is being restored to its original appearance by the Borough of Northumberland, Pennsylvania, U.S.A. This house, started in 1795 and completed in 1797, and owned for many years by the Priestley family, was purchased in 1920 by the Pennsylvania State University and presented this year (1956) to Northumberland. The home is of Georgian architecture, is in fine condition, and occupies an acre of landscaped ground near the Susquehanna River. Under the direction of the Priestley Mernorial Association, the widow's walk, kitchen and laboratory are being restored to their original appearance and the rooms refurnished with American furniture of about 1800. The Association desires to gather all obtainable information on Priestley and on his American home. It would like to receive reprints of articles bearing on his work, and it welcomes correspondence with anyone interested in this matter; visitors are welcome. Correspondents should write to Mr. Lewis K. Rich, 464 Front Street, Northumberland, Pennsylvania.

The Division of History of Chemistry of the American Chemical Society is co-operating with the Priestley Memorial Association in the restoration of Priestley's laboratory. To this end a committee including Sidney Edelstein, Claude K. Deischer and Wyndham Miles (chairman) has been constituted. The committee wishes to locate apparatus of Priestley's American period, with the view of acquiring them or having replicas made. It welcomes correspondence with anyone knowing the whereabouts of apparatus, and with scholars interested in this project; correspondence should be addressed to Dr. Wyndham Miles, Edgewood, Maryland.

\section{Science and the Humanities}

What is pothenology? Sir Gavin de Beer tells us in his Rickman Godlee Lecture on "Science and the Humanities", delivered on October 25 at University College, London (London : H. K. Lewis and Co., Ltd. 2s. 6d. net). Much harm is done, in his opinion, by ignoring the essential differences between the collectors of Nature's answers and the compilers of men's thoughts. In a witty survey 